\title{
Ato Adicional e Unidade Nacional
}

\section{Aldo Janotti}

Departamento de História da FFLCH da Universidade de São Paulo

Sedições, motins, movimentos restauradores, repúblicas provisórias ou pretensiosamente definitivas, uma nação conturbada, eis o panorama político do Brasil regencial. Porque os anos da Regência foram os mais críticos do nosso desenvolvimento histórico, nunca esteve o Brasil tão seriamente ameaçado de desintegrar-se num sem número de outras formações geo-políticas. Consequentemente, nunca tantos esforços foram despendidos com o objetivo de se preservar a unidade nacional. Unidade nacional: a grande preocupação da Regência.

A referida preocupação se manifestava mediante desdobramentos os mais diversos. Sob o aspecto institucional, por exemplo, preservava-se a Monarquia contra os seus inimigos, uma vez que ela era vista como o único regime capaz de manter unido um país tão vasto como o Brasil; sob o aspecto partidário, combatiam-se os restauradores, considerados perigosos para a mantença da união. Mas a preocupação com a unidade nacional não parava aí, continuava: desde que o Exército era tido pela maioria dos parlamentares e pelos magistrados executivos como o grande instrumento de conservação da unidade, nem efetivos militares $\mathrm{e}$ nem recursos financeiros poderiam faltar-lhe; créditos suplementares requeridos pelo Govêrno eram aprovados pela Câmara dos Deputados pela necessidade de "chamar as províncias do Pará e do Rio Grande à ordem, 
à integridade" (1). Cautela devia haver na aplicação dos impostos, pois se estes fossem de natureza provincial e não geral, deviam ficar na Província para atender às suas necessidades e não sair, para atender às necessidades do Império: desviar o dinheiro da Província, aplicando-o fora dela, poderia trazer graves consequiências, a dano da unidade nacional. As Falas do Trono eram a própria voz do lamento, do temor e da súplica: em 1836 o Regente Feijó informava à Câmara dos Deputados que a Província do Pará ainda não fora "arrancada às feras que a dominam", que a sedição de Porto Alegre rapidamente se estendera por todo o Rio Grande do Sul e, assim, "o vulcão da anarquia ameaça devorar o império, aplicai a tempo o remédio" (2). Em resposta às Falas do Trono, a Câmara dos Deputados através da sua competente comissão prometia à Regência que seria solícita em prevenir os possíveis conflitos entre os poderes nacionais e as assembléias provinciais, a fim de que "possam as mesmas assembléias deliberar com mais segurança e sem o risco de exorbitarem e invadirem os poderes do estado, e destruirem destarte os fundamentos da união do império" (3); promoções - mais especificamente, nos postos da carreira militar - para aqueles que tinham se distinguido "... na manutenção da ordem pública, quando ameaçada, ou perturbada em crises tão funestas como as que oferece a rebelião, a sedição e a insurreição" (4); recompensa pecuniária, ou gratificação de campanha correspondente à terça parte do respectivo soldo, além dos demais vencimentos, "a todos os indivíduos que fizerem parte das expedições a qualquer parte do império, ou nele se achando conjuntamente cooperarem para o restabelecimento da ordem" (5); punição exemplar para os que atentarem contra a unidade nacional, a ponto dos cabanos do Pará deverem ser tratados como feras; perdão, esquecimento, anistia enfim depois de pacificada a Provincia sediciosa - para preservar a unidade do país, desarmando os espíritos; um deputado entre outros, Rodrigues Torres, censurava o Govêrno pela política que adotava relativamente à Santa Sé: para êle, um atentado à religião de nossos pais podia atear o facho da guerra civil (6); Limpo de Abreu, Ministro dos Estrangeiros, chamava a atenção quanto ao perigo de, na Câmara dos Deputados, se pretender desmoralizar tanto o Govêrno quanto os seus funcionários: "Senhores, numa população ilustrada como a do Rio de Janeiro, tais vozes não hão de produzir efeito algum; mas onde a ilustração não for tamanha, tais vozes são um archote (permita o céu que eu me engane),

(1) - Anais do Parlamento Brasileiro - Câmara dos Srs. Deputados, sessão de $1 / 9 / 1836, I$, p. 243.

(2) - Idem, sessão de $3 / 5 / 1836, I$, p. 14 .

(3) - Idem, sessão de 7/5/1836, II, p. 23.

(4) - Idem, 1835, I, p. 116.

(5) - Idem, sessão de 13/9/1836, II, p. 293.

(6) - Idem, sessão de $15 / 5 / 1836, \mathrm{I}, \mathrm{p} .45$. 
são um archote de guerra civil, e talvez da desunião de todas as províncias" (7).

Em tudo e por tudo havia a preocupação com a unidade nacional. Às vezes até sob aspectos que chegavam aos limites da bizarrice, para não dizer do ridículo. A 2 de agosto de 1834, a Câmara dos Deputados discutiu uma proposta de resolução do Conselho Geral da Província de São Paulo. Pedia ele autorização para criar um curso de ciências sociais. Houve debates. Uns deputados justificaram sua posição contrária, sob o argumento de que era pernicioso estimular os homens para esses conhecimentos sociais, porque ficavam mais aptos para promover "rusgas"; outros, pronunciaram-se a favor e exatamente pela razão contrária: quanto mais instruidos fossem os homens nos seus deveres e nos seus direitos tanto mais difícil seria a promoção de atos insurrecionais que prejudicassem a sociedade (8). A proposta do Conselho paulista não foi aprovada!

Do mesmo modo, sob o aspecto da reforma constitucional não deixava de se fazer sentir a preocupação com a unidade nacional. Através de diferentes maneiras se manifestava tal preocupação. E a primeira por si só já estava relacionada com a própria necessidade de se reformar a Constituição.

Com efeito, em fins de 1831 tinha sido aprovado um projeto de reforma, baseado no substitutivo de Miranda Ribeiro, e enviado ao Senado com o aditivo "o govêrno do império do Brasil será uma monarquia federativa". O Senado, no entanto, por um lado visceralmente atingido pelo projeto no tocante à vitaliciedade dos seus membros que era abolida e por outro não concordante com o sentido nitidamente liberal, federalista e descentralizador do mesmo, adiava a sua discussão para o ano seguinte. E nesse ano, 1832, não dava mostras de que tão cedo se pronunciaria. Tal atitude protelatória do Senado face à reforma logo despertou a reação da Câmara dos Deputados. E que a reforma era considerada como necessidade inadiável para não se colocar em risco a unidade da Nação. Consequentemente, hostilizou-se o Senado. Para Odorico Mendes, o Senado parecia não desejar a reforma, advertindo, porém, que o Rio de Janeiro não era o Brasil e que as províncias a queriam. Do mesmo parecer eram Caetano de Almeida e Costa Ferreira. Para este último, o Senado estava perro e não queria a reforma, atacando violentamente os senadores (9). Dias após, Costa Ferreira voltava a atacar - Senado, e desta vez mais violentamente ainda: queriam sabotar a refor-

(7) - Idem, sessão de 28/9/1836, II, p. 370 .

(8) - Idem, 1834, II, p. 184-5.

(9) - Idem, sessão de 16/6/1832, I, p. 110-1 
ma, levianamente não percebendo que prestes arrebentaria o vulcão sobre o qual o Brasil estava sentado (10).

Odorico Mendes, tornando à questão, fornecia-nos elemento importante para compreendermos a resistência do Senado. Segundo ele, o Senado estava a par que se queria a reforma, mas que provavelmente se negava a deixar passá-la pelo temor de que algumas províncias se desligassem do Império (11). Percebe-se através die Odorico Mendes o quanto de dialético havia relativamente à preservação da unidade nacional. A Câmara dos Deputados estava disposta a uma descentralização avançada a fim de que as províncias, com maior liberdade de ação, continuassem ligadas ao Império. O Senado temia que as províncias se desligassem caso se aprovasse a disposição da Câmara. Dessa forma, o objetivo era um só - a unidade nacional _, e que deveria ser atingido mesmo através de meios opostos. Aliás, tal processo dialético não se manifestava apenas nas relações entre a Câmara e o Senado. Na própria Câmara - como do mesmo modo no Senado, posto que com ele não nos preocupemos -, manifestava-se a dialética da unidade nacional. Vejamos um dos muitos exemplos. Em 1831, na sessão de 17 de maio, Lino Coutinho afirmava: 'Desenganemo-nos senhores, se não se afrouxar o nó apertado do govêrno central, não é possível conservar o Brasil unido. Este não é semenlhante ao nó físico: quanto mais apertado, tanto mais depressa arrebenta". A seguir, passava Lino a ponderar os inconvenientes de sairem indivíduos de províncias distantes, como a do Pará, por exemplo - de onde era mais fácil a viagem para a Europa do que para a Capital do Império - a fim de solicitar no Rio de Janeiro o provimento de um emprego de $100 \$ 000$, depois de arrostar os perigos e dispêndios de uma longa viagem. E acrescentava que era impossível conservar as províncias em estado preternatural, pois não havia povo que quisesse estar assim tão apertado e oprimido; pelo contrário, todos queriam que a sua província tivesse certos meios administrativos, certo governo que tendesse a promover o bem particular da mesma, e no qual ia igualmente compreendido o bem geral do Império (12). Respondendo, Carneiro da Cunha propôs-se a combater as afirmações de Lino Coutinho "de que as províncias se não tivessem a amplitude necessária para arranjarem os seus negócios particulares e para tratarem de promover o seu bem, haviam de disunir-se e terão de separar-se infalivelmente". Propôs-se ainda a combater todas as idéias tendentes a insinuar a independência das províncias, mostrando os riscos, como sucedeu na América Espanhola, delas se desligarem do centro comum: as grandes quererão dominar as pequenas, estas, para escaparem ao jugo daquelas, procurarão aliar-se às outras que lhes ofereçam mais vantagens e assim, consequentemente, estará

(10) - Idem, sessão de 20/6/1832, I, p. 119.

(11) - Idem, 1832, I, p. 120.

(12) - Idem, 1831, I, p. 48. 
ateada a guerra civil, seguida de todos os horrores que a acompanham (13).

Na sessão de 30 de julho, Odorico Mendes voltava a falar que o Se nado continuava a negar a reforma que as províncias estavam dispostas a obter, alertando que a atitude deste podia trazer a guerra civil e atentar contra a preservação da unidade nacional (14). Em agosto, como o Senado tivesse enviado à Câmara emendas à reforma constitucional, Henriques Rezende requereu urgência para a discussão das mesmas, "por estarem a partir para o Norte os paquetes, que muito convem que levem as notícias da decisão de tão importante matéria, para previnir qualquer comoção que possa aparecer nas províncias", (15) uma vez que nada havia de mais urgente do que tratar-se da reforma constitucional, esperada pelas províncias com ansiedade (16).

A oposição Câmara-Senado acabou resultando num acordo. A Câmara, consequência da "debandada" da maioria governista com a malograda tentativa do golpe de Estado de 30 de julho de 1832, inclinava-se a ceder alguma coisa em relação ao radicalismo que adotara no seu projeto de reforma do ano anterior e o Senado, por sua vez, também cedeu optando afinal por uma atitude mais prudente (17). Esse acordo ou transação foi celebrado nas sessões conjuntas da Câmara e Senado em setembro, do qual resultou a lei de 12 de outubro de 1832, autorizando os eleitores da legislatura 1834-1837 a concederem poderes especiais aos deputados para reformarem vários artigos da Constituição de 1824 . As bases do acordo foram estas: supressão do Conselho de Estado, manutenção do Poder Moderador e da vitaliciedade do Senado; os Conselhos Gerais poderiam ser tranformados em Assembléias Legislativas; teria Assembléia Legislativa e capital própria onde estava instalado o Govêrno-Geral; a sede do Govêrno-Geral constituia-se em Município Neutro; aceitas a discriminação de rendas e divisão dos poderes tributários; rejeitada a autonomia municipal; e a Regência Trinta poderia tornar-se Una. Conforme essas bases é que iria surgir o Ato Adicional (12 de agosto de 1834).

Logo no início das discussões da reforma da Constituição já aflorava uma outra preocupação relativamente à unidade nacional: se o Senado deveria participar ou não das discussões juntamente com a Câmara. Uns eram partidários da reunião conjunta, outros de que somente a Câmara deveria proceder à reforma. Souza Martins pronunciou-se a favor

(13) - Idem, 1831, I, p. 48.

(14) - Idem, 1832, II, p. 132.

(15) — Idem, sessão de 28/8/1832, II, p. 205.

(16) - Idem, sessão de 29/8/1832, II, p. 213.

(17) - Castro, Paulo Pereira de. A "Experiência Republicana", 1831-1840, in História Geral da Civilização Brasileira, dir. Sérgio Buarque de Holanda, São Paulo, Difel, 1967, t. II, v. II, p. 30. 
da presença do Senado, argumentando, "se na câmara dos deputados, uns são de opinião que só a câmara deve tratar das reformas, outros que o senado deve concorrer com as suas luzes, quem asseveraria que nas províncias não houvessem partidos que não aoeitassem as reformas a título de não serem filhas de ambas as casas? Não seria isto dar lugar a que se desenvolvam partidos, podendo-se obrar de harmonia com a outra câmara, para evitar quaisquer acontecimentos que pudessem aparecer por este respeito?". E continuando a sua argumentação, toda ela preocupada e preocupante com a unidade brasileira, Souza Martins achava necessário observar que nos Estados Unidos o Congresso, para dar maior força às suas decisões, usava de uma fraude que julgava conveniente, qual fosse a de mostrar que as suas relações eram tomadas pela unanimidade a fim de que a nação toda, mediante tal processo, acreditasse seus representantes em harmonia, evitando assim possíveis dissenções (18). Já Evaristo da Veiga, adotando atitude oposta, era partidário de que somente a Câmara dos Deputados é que tinha o direito de fazer a reforma. E, mais do que o direito, o interesse: receava muito pela sorte da reforma caso o Senado interviesse nela, visto que "julgava que se a reforma não passasse, o Brasil talvez sentisse a guerra civil" (19) . O arcebispo da Bahia também era a favor da participação do Senado, confessando-se temeroso de uma revolução (20). Luis Cavalcanti foi claro quanto a competência exclusiva da Câmara: falou-se "que parte da população brasileira não quererá obedecer; o remédio é obvio; publiquemos as nossas falas, as razões em que nos fundamos, ie mostremos que obedecemos à constituição escrita, e não há de haver revolução, porque a câmara dos deputados é a única competente para todas as reformas" (20).

Através de caminhos diferentes, com o Senado ou sem ele, procurava-se chegar ao mesmo fim: a preservação da unidade nacional. Por ampla maioria, depois de prolongadạs discussões, a Câmara dos Deputados deliberou que o Senado não devia, juntamente com ela, participar da reforma da Constituição (22). Esboçou-se mais tarde no Senado uma tentativa de inconformada reação. Informa-nos Antônio Pereira Pinto, o compilador dos Anais, que o Senado protestou contra tal deliberação, chegando o senador José Saturnino da Costa Pereira a apresentar indicação para que este declarasse ilegal a reforma constitucional, adotada pela Câmara e sem a intervenção dos senadores. Muitos senadores falaram, e não houve muita discrepância quanto ao direito que competia ao Senado de participar da elaboração da reforma. Carneiro de Campos,

\footnotetext{
(18) - Anais, sessão de 14/6/1834, I, p. 134.

(19) - Idem, 1834, I, p. 136.

(20) $)^{\prime}$ Idem, 1834, I, p. 140.

(21) - Idem, 1834, I, p. 148 .

(22) — Idem, sessão de 17/6/1834, I, p. 149.
} 
porém, manifestou-se francamente contrário a qualquer atitude do Senado no sentido pretendido por Saturnino da Costa Pereira, acoimando a sua indicação de anáquica e revolucionária. E Paula Souza imediatamente procurou e conseguiu pôr termo à perigosa possibilidade de um conflito de ordem interparlamentar, impressionado também pelo temor das várias dificuldades políticas que se abateriam sobre o país, em época ainda crítica (23). Enfim, o que importava era não se dar motivo que pudesse fazer com que corresse risco a unidade nacional: tudo se lhe devia estar subordinado.

Vejamos agora no que, mediante alguns exemplos, as discussões sobre a reforma da Constituição evidenciaram preocupação com a unidade. Henriquez Rezende pretendia facultar às províncias 0 direito de aceitar ou não a reforma constitucional. Para Saturnino de Souza Oliveira a idéia de Rezende iria por em combastão todas as províncias do Brasil, explicando seu temor da seguinte maneira: segundo ele, ainda que o partido reformista fosse efetivamente muito grande, não deixava no entanto de haver anti-reformistas, cujo partido - no caso de adotar-se a sugestão de Rezende -, não deixaria de usar o direito de emitir o seu voto, o que "irá talvez daqui suceder a guerra civil, para decidir-se se há de ou não aceitar a reforma". E não deixava Saturnino escapar a oportunidade para admoestar Rezénde de não ter refletido bem a respeito desse inconveniente (24). $\mathrm{Na}$ sessão de 28 de junho, Costa Ferreira afirmava que mandaria à Mesa da Câmara uma emenda referente a "uma coisa, que parecia podia conceder, sem receio dos senhores que tanto temem que se quebrem os laços que atam o Brasil". A emenda de Costa Ferreira visava dar às províncias a liberdade de delimitar o tempo de duração das suas assembléias - que podia ser de um dois, três, quatro anos, a gosto de cada província -, sob o argumento que "nada faz isto que seja contra a harmonia social do Brasil" (25). A emenda de Costa Ferreira não foi absolutamente levada em conta, pois aprovou-se que o prazo de cada legislatura provincial duraria uniformemente só dois anos. Paula Araujo colocou-se também contra uma emenda que pretendia conceder à Assembléia Provincial faculdade para ela própria prolongar a sessão além do tempo estipulado no projeto de reforma (dois meses). E fundamentava a sua posição: seria perigoso deixar às assembléias provinciais tal faculdade, porque seus membros podiam ser dominados por uma facção que não estivesse em harmonia com os interesses da Província, facção que coagiria a Assembléia, "e isto podia trazer funestos resultados, a guerra civil" (26). Sa-

(23) - Idem, 1834, I, p. 149.

(24) - Idem, sessão de 25/6/1834, I, p. 175 .

(25) - Idem, 1834, I, p. 196.

(26) - Idem, sessão de 30/6/1834, I, p. 206. 
bemos que quanto à duração da sessão de cada legislatura da Assembléia Provincial ficou decidido que duraria dois meses, podendo ser prorrogado quando julgar conveniente o presidente da Província (27).

Relativamente ao presidente da Província, igualmente notamos na reforma constitucional referências inerentes à unidade. Holanda Cavalcanti era contra que se desse a ele poderes para intervir na administração econômica da Província. Na opinião dele, caso se pretendesse dar-lhe tal poder, que se o fizesse por meio de uma lei ordinária, pois que se aparecessem males era mais fácil remediá-los: "que não se fosse comprometer a união do império, e depois não poder obstar a ela senão por uma revolução, por não haver tempo de remediar o mal produzido por uma lei constitucional" (28). Limpo de Abreu - que juntamente com Bernardo Pereira de Vasconcelos e Paula Araujo era membro da comissão de reforma da Constituição -, teceu considerações em torno do fato de Holanda Cavalcanti ser de opinião que o presidente deveria ser considerado como um diplomata na sua província. Ironizando, Limpo de Abreu declarou que "entendia (..) até aqui" ser o diplomata um funcionário público nomeado pelo Govêrno de um país qualquer para exercer certa comissão num país estrangeiro; que o que queria Cavalcanti outra coisa não era senão soberanizar as províncias, isto é, estrangeirá-las, ou seja ainda, para que as províncias formem governos estrangeiros; parecendo-lhe, a título de advertência, "que ninguém poderá pronunciar-se por esta idéia do $\mathrm{Sr}$. deputado, e podem algumas pessoas que não estão bem certas nas intenções do $\mathrm{Sr}$. deputado entenderem que ele se persuade que as províncias devem, pela reforma, ficar como estados estrangeiros no Brasil" (29). Por outro lado, Costa Ferreira insurgiu-se quanto à intenção de dar-se ao presidente - que, note-se, será nomeado pelo Governo central - competência para sancionar leis e resoluções da Assembléia Provincial. Queixava-se ele que se queria que tudo ficasse ao bel prazer do presidente, "que pode não sancionar as leis, e jogar as cristas com a assembléia provincial, porque pode dizer que uma lei ofende aos tratados, outra aos interesses gerais etc.", ficando o problema suspenso na Província para ser resolvido no Rio de Janeiro; e ainda mais, se o presidente entender que uma questão tem correlação com outra província, poderá acontecer que ele não queira sancionar o projeto a ela referente e desejar que a solução seja encontrada na capital do Império (30). Aliás, Costa Ferreira era um dos partidários da tendência de que havia a necessidade de se federalizar o Brasil - no sentido de se dar maior liberdade às províncias —, exatamente para evitar-se a sua desunião. No seu entendimento, era preciso que o Brasil fosse

(27) - Art? 7 do Ato Adicional.

(28) - Anais, sessão de $1 / 7 / 1834, \mathrm{II}$, p. 8.

(29) - Idem, 1834, II, p. 9.

(30) - Idem, sessão de 8/7/1834, II, p. 49. 
federalizado para que se tirasse todo o pretexto a homens desordeiros, "e que as províncias fiquem livres dessa tutela, dessa centralização, ou para melhor dizer, escravidão"; era necessário conceder-se às províncias o que lhes competia e deixar tão somente ao Govêrno central o que se refere a objetos gerais; nada se faria caso se procedesse diferentemente, pois "o melhor meio de unir o Brasil era dar o que pertence aos povos, dar às províncias o que pertence às províncias; de outro modo temia desordens, e portanto devia-se federar o Brasil quanto antes" (31). Queria portanto Costa Ferreira evitar a excessiva centralização, personalizada no presidente provincial. Evaristo da Veiga respondeu-lhe, definindo primorosamente o presidente provincial como um baluarte do poder central, isto é, um elemento cuja função era a de manter a unidade nacional: "O presidente é, além da expressão da província, a expressão da vontade nacional, como delegado do poder nacional, representa na província de algum modo os interesses nacionais que lhe foi incumbido vigiar" (32).

Ainda vinculadas à conservação da unidade nacional encontramos manifestações dos deputados relacionadas com as assembléias provinciais. Em lugar do artigo 12 do projeto de reforma que proibia às assembléias provinciais legislar sobre impostos de importação e sobre objetos não compreendidos nos dois artigos precedentes, Batista Caetano, com o intuito claro de beneficiar as províncas centrais ou continentais - de preferência Minas Gerais -, propôs um artigo que o substituisse. O artigo substitutivo de Batista Caetano dizia o seguinte: "As assembléias provinciais legislativas não poderão legislar sobre importação nas alfândegas marítimas" (33). Tanto Paula Araujo quanto Gonçalves Martins não concordaram com tal artigo substitutivo. Para o primeiro, se aprovado ele, ficavam algumas províncias autorizadas a legislar sobre a importação de outras províncias o que, além de inconveniente, parecia-lhe injusto: "... seria considerar as províncias como estados separados, e dava motivos a conflitos entre província e província, e talvez a guerra civil: e via nesta emenda reproduzida uma proposta do conselho geral de Minas, que não devia ser aprovada do modo algum" (34). Para o segundo, Gonçalves Martins, ele "autorizava as províncias centrais a impor sobre objeto de importação estrangeira, não tendo as províncias marítimas este direito". Exemplificando Martins ao que se poderia chegar mediante o substitutivo de Batista Caetano, mostrava que os gêneros de importação estrangeira não podiam ser taxados pela Assembléia Provincial do Rio de Janeiro mas, assim que deixassem aquela província, poderiam ser taxados pela de Minas. Dessa forma, conseguia-se o absurdo de Minas Gerais cobrar direitós sobre um objeto estrangeiro, coisa que

(31) - Idem, 1834, II, p. 27.

(32) - Idem, 1834, II, p. 49.

(33) - Idem, sessão de $8 / 7 / 1834$, II, p. 47.

(34) - Idem, 1834, II, p. 48. 
não podia fazer o Rio de Janeiro, por onde ele entrava no país (35). Não foi aprovado o artigo substitutivo de Batista Caetano. Na sessão de 12 de julho, Bernardo Pereira de Vasconcelos explicava porque era a favor que as assembléias provinciais pudessem exercer, provisoriamente, o direito de suspender as leis: "... atendendo à distância do Brasil, e para ocorrer a uma medida de salvação, quando em alguma província se tivesse manifestado uma rebelião ou invasão de inimigos" (36).

Referências à preocupação com a unidade do Brasil, encontramos inclusive na maneira pela qual o Regente deveria ser eleito. Rodrigues Torres não concordou com a emenda que desejava a eleição do Regente por um voto de cada província, argumentando que, se para dirigir os interesses puramente provinciais se pretendia criar uma Assembléia Legislativa - cujo número de membros não tinha relação com a população de cada província -, no que se referia, porém, à nomeação de um regente, ou seja, de um representante dos interesses da totalidade dos cidadãos brasileiros, cumpria que cada fração de população tivesse nela proporcional influência (37). Não fosse assim e se estabeleceria a rivalidade entre as províncias. E Bernardo Pereira de Vasconcelos, embora fazendo "votos para que fossem todas as províncias igualadas como convem ao bem do império", não via como seria possível que uma província que só conseguiu eleger um deputado pudesse ter um voto igual àquela que estivesse em condições de eleger treze. Para ele, permitir que cada província tivesse um voto independentemente da sua população, corresponderia a se colocar obstáculos àquilo que mais se queria, ou seja, o "grande princípio da representação, e representação em atenção à população", possibilitando-se dessa forma a que não fosse a maioria forçada a sujeitar-se à minoria (38). Contrapondo-se a esses argumentos, Rego Barros sustentou que terrível rivalidade se estabeleceria entre as províncias caso prevalecesse o que pretendia a comissão de reforma da Constituição, isto é, a eleição do Regente proporcionalmente à população provincial, pois ela faria "com que uma província prepondere sobre as outras, $\dot{\mathrm{e}}$ lhes dite a lei" (39). Outrossim. não se aprovou que a eleição do Regente se fizesse pela Assembléia Geral do Império, e sim pelos eleitores da respectiva legislatura. Evaristo da Veiga, combatendo aquele pretendido processo de eleição, aludia à possibilidade de que, na pressuposição de que ele fosse aprovado, pudesse gerar perigosa e inconveniente disputa entre o Senado e a Câmara dos Dsputados: "Instituir-se-á uma luta no Estado? Queremos que essa luta se institua? Saberemos quais são as suas consequências? E de homem prudente e circunspecto temer toda idéia revolucionária, e mesmo preve-

(35) - Idem, 1834, II, p. 48.

(36) - Idem, 1834, II, p. 77.

(37) - Idem, sessão de 16/7/1834, II, p. 97.

(38) - Idem, 1834, II. p. 101.

(39) - Idem, 1834, II, p. 111. 
nir a que se chegue a uma tal crise" (40). Já Rego Barros - favorável como já vimos à eleição do Regente por um voto de cada província -, externava as opiniões seguintes, mas sempre tendo em vista a harmonia interprovincial: não era a favor que o Regente fosse escolhido como pretendia a comissão de reforma — pelos eleitores do Império -, sob o pretexto de que não havendo estatísticas não se poderia fixar ao certo o número de eleitores que cada província estivesse em condições de fornecer, defeito que levaria cada uma delas a, ficticiamente, aumentar o número dos mesmos; era contra aqueles que queriam a eleição do Regente pelas assembléias provinciais, uma vez que "não tendo sido guardada uma proporção exata no número dos membros das assembléias provinciais, viriam os votos do norte e preponderar sobre os do sul" (41). E Paula Araujo, também revelando cuidados para que a ordem não encontrasse motivos de ser rompida, combateu emendas que tinham por finalidade criar a figura do Vice-regente. Para ele, o Vice-regente seria o foco polarizador dos descontentes, certamente agrupados no partido que não tivesse triunfado na eleição para Regente, a exemplo do que acontecia com o Vice-presidente das repúblicas sulamericanas. Como Costa Ferreira, a propósito da questão, the perguntasse porque não ia ele buscar o exemplo da América do Norte, exemplo muito mais valioso do que desses povos que estavam sempre em anarquia, Paulo Araujo, realisticamente, não titubeou ao responder-lhe: "que devia procurar exemplos do povo que estivesse em circunstâncias mais aproximadas às nossas, e ninguem dirá que as nossas circunstâncias são mais semelhantes às dos povos da confederação do norte, do que ao das ex-colônias espanholas" (42).

As manifestações de preocupação com a unidade nacional, que fartamente acreditamos ter mostrado nas discussões da reforma da Constituição, por certo que acabariam se refletindo na Historiografia. Tais manifestações caracterizam-se por um sentido nitidamente dialético - o Senado protelando a reforma mas a Câmara dos Deputados apressando-a, se o senado participaria ou não das discussões a respeito dela, se devia haver descentralização ou centralização, se as províncias poderiam gozar ou não da faculdade de aceitá-la, se a Assembléia Provincial teria ou não liberdade quanto à duração das legislaturas, se o Presidente interviria ou não na administração econômica da Província e se ele sancionaria ou não leis e resoluções da Assembléia Provincial, se esta legislaria ou não sobre impostos de importação, se o Regente deveria ser eleito pela Assembléia Geral ou pelos eleitores do Império, se havia necessidade ou não de Vice-regente gar a um objetivo comum, qual seja o evitar-se a persistência de motivos que pudessem ocasionar o desmembramento da Nação, tal como ocorrera

(40) - Idem, sessão de $16 / 7 / 1834$, p. 104 .

(41) - Idem, sessão de 17/7/1834, II, p. 110 .

(42) - Idem, sessão de 19/7/1834, II, p. 118. 
na América Espanhola, modelo que, constante e insistentemente lembrado, a qualquer custo não deveria ser seguido.

Da mesma forma, deparamo-nos na Historiografia com um tratamento dialético quando ela, erigindo-se em julgadora do Ato Adicional, procura interpretá-lo segundo a perspectiva da unidade nacional. Estamos em preşença de uma controvérsia que já vem de longe e chega até os dias de hoje. Para uns, o Ato Adicional contribuiu para fortalecer a unidade nacional. Para outros, ele contribuiu sim mas no sentido de enfraquecê-la. Apenas para exemplificar, até porque não é este o momento e o lugar de nos preocuparmos exaustivamente com a questão, contentamo-nos com dizer que Sales Torres Homem no Libelo do Povo viu - Ato Adicional como "o único liame, que pôde manter então ligadas entre si as dezoito estrelas do pavilhão imperial" (43). Justiniano José da Rocha, porém, em Ação; Reação; Transação encontrava nele o germe da anarquia e da ruina da unidade brasileira: “... se alguma assembléia provincial, bem dirigida por estadistas que compreendiam quanto a bem da administração dos recursos provinciais podia fazer essa instituição, preparava os elementos de prosperidade, e caminho dos melhoramentos, outras começavam a desvairar-se, e já iam mostrando duas tendências fatais; uma para criar antagonismos de interesses territoriais e fiscais entre as províncias, outra para alterar a legislação, transformá-la, e acabando com a unidade dela, acabar com a unidade do Brasil" (44). Isto diziam, contrapondo-se um ao outro, os dois célebres publicistas do século passado. Mas historiadores mais recentes procedem da mesma maneira. Para Aurelino Leal, o futuro se incumbiu de mostrar que o Ato Adicional "era imprestável para realizar os intuitos visados pelos seus autores", pois não permittiu que os dois govêrnos, o geral e o provincial, atuassem harmonicamente, o primeiro contrastando o segundo, embora deixando-lhe aquela porção de autonomia decorrente da descentralização administrativa" (45). No entanto, Otávio Tarquínio de Souza interpretou-o como uma obra de transação que apaziguou o espírito regional nos seus justos reclamos sem desamparar a autoridade do Govêrno central, uma vez que as franquias provinciais "ao invés de concorrerem para desunir, deram nova feição à unidade nacional, numa unidade que não pode excluir a variedade, a diversidade das diferentes regiões do puís tão vasto e tão disperso" (46).

Mais importante, porém, do que a dialética interpretativa da Historiografia, externada por publicistas e historiadores, é aquela que, quanto

(43) - In Magalhães Júnior R. Três Panfletórios do Segundo Reinado, São Paulo, Cia. Editora Nacional, 1956, p. 89.

(44) - In Magalhães Júnior R. loc. cit., p. 193.

(45) - "O Ato Adicional", in Revista do Instituto Histórico e Geográfico Brasileiro, Rio de Janeiro, 1916, Primeiro Congresso de História Nacional, III, p. 125. 1960 , p. 129 . 
ao Ato Adicional, pensando e agindo, expressaram as " personagens da própria História. Que intuito visavam os autores do Ato Adicional? $\mathrm{E}$ mais do que evidente que ele é sabidamente conhecido. Em todo caso, não deixa de ser conveniente observar que Limpo de Abreu, ao apresentar à Regência os autógrafos do texto do Ato Adicional para a sanção, pronunciou importante discurso. Nele, o futuro Visconde de Abaeté, considerando que na reforma da Constituição a capacidade nacional prevaleceu acima das mesquinhas considerações locais, que os objetos provinciais achavam-se cautelosamente descritos e delimitados, pediu "que V.M. o I. se digne de mandar promulgar esta lei da reforma, penhor da união das províncias" (47). Como penhor da união das províncias referiu-se Limpo de Abreu ao que logo mais - 12 de agosto de $1834-$ seria o Ato Adicional!

Todavia, estava-se ainda em plena discussão do projeto do Ato Adicional, e já o seu principal elaborador e redator, Bernardo Pereira de Vasconcelos, manifestava seu inconformismo face às desfigurações que sofria, como resultado de emendas que a Câmara dos Deputados aprovava. Fernandes Silveira na sessão de 11 de julho de 1834 acusava Bernardo de ter dito, se bem se lembrava, "que este projeto em discussão era a carta da anarquia que ia para as províncias" (48). Nasce daí a famosa versão segundo a qual, ao entregar aos seus companheiros da Comissão de reforma a redação final do projeto, feita conforme as emendas votadas pela Câmara, Bernardo dissera:: "Entrego-lhes o código da anarquia". E não há porque não acreditar na referida versão. Já tinha sido inclusive acusado na Câmara de assim se referir e, posteriormente, c próprio Bernardo por ocasião da sessão do Senado de 29 de maio de 1839, como que irá confirmá-la: "Eu entendi que o Ato Adicional devia ser aprovado tal qual o redigi e apresentei na Câmara dos Deputados. Não consegui o meu desejo; fizeram-lhe consideráveis emendas que o podem tornar, como eu receava, a carta da anarquia, se o Senado, a Câmara dos Deputados e o Poder Moderador não promoverem a sua interpretação de maneira tal que os diversos elementos governativos se não combatam" (49). Assim, o próprio criador daquilo que criara em nome do princípio da unidade nacional renegava sua desfigurada criatura que não atendia às necessidades do princípio pelo qual fôra criada. Mais do que renegava, e sempre atendendo à unidade nacional que a tudo $\mathrm{e}$ a todos comandava, Bernardo queria a interpretação do Ato Adicional, equivalendo isto a dizer, a sua liquidação.

Que se interpretasse o Ato, caso ele não atendesse à finalidade para que fôra adotado. Como, aliás, parecia não atender se considerarmos

(47) - Apud Torres. João Camilo de Oliveira, A Democracia Coroada, 2. ed., Petropolis, Editora Vozes, 1964, p. 440.

(48) - Anais, 1834, II, p. 70.

(49) - Apud Aurelino Leal, op, cit., loc. cit., p. 126. 
que não muito tempo depois da sua promulgação explodia a revolução farrapa. Na opinião de Paulino José Soares de Souza, foi uma emenda apresentada por Paula Araujo ao artigo 10 do Ato Adicional que deu lugar a todas as complicações que posteriormente apareceram no já muito complicado Brasil. Tal emenda não constava do projeto redigido por Bernardo. A discussão do artigo 10, dispondo a respeito dos assuntos da competência das assembléias provinciais, demandou várias sessões (2 a 5 de julho). Numa delas, Paula Araujo apresentou sua emenda que se acrescentou ao referido artigo na qualidade de parágrafo $7^{\circ}$. Determinava ele textualmente o seguinte no "caput" - "Compete às mesmas assembléias legislar": "Sobre a criação, supressão e nomeação para os empregos municipais e provinciais, e estabelecimento dos seus ordenados. São empregos municipais e provinciais todos os que existirem nos municipios e províncias, à exceção dos que dizem respeito à arrecadação e dispêndio das rendas gerais: à administração da guerra e marịnha, e dos correios geraiso dos cargos de presidente de província, bispo, comandante superior da guarda nacional, membro das relações e tribunais superiores, e empregados das faculdades de medicina, cursos jurídicos e academias, em conformidade com a doutrina do $\S 2^{\circ}$. deste artigo". Nos seus Ensaios sobre o Direito Administrativo, Paulino Soares de Souza sentenciou: "Esta declaração e enumeração, que se contêm na segunda parte do $\S 7^{\circ}$. do art. 10 do Ato Adicional $(. .$.$) é a causa principal de toda$ a confusão e conflitos que se têm dado entre as atribuições do poder geral e provincial" (50).

Que se interpretasse o Ato Adicional. Outrossim, no próprio texto do Ato havia a possibilidade da sua interpretação, visto que - conforme dispunha seu Artigo 25 -, no caso de dúvida sobre a inteligência de algum artigo da reforma constitucional, competia ao poder legislativo geral interpretá-lo. Dúvidas havia e não apenas quanto à inteligência de algum artigo do Ato Adicional mas sim quanto a todo o Ato em si como instrumento eficaz da preservação da unidade nacional. Já em julho de 1835, Souza Martins havia apresentado um requerimento para que as comissões das assembléias provinciais e de constituição reuindas redigissem um projeto interpretando os artigos mais obscuros ou duvidosos do Ato Adicional. Álvares Machado, no entanto, pronunciou-se contrariamente ao requerimento, invocando que as circunstâncias do momento eram demasiadamente "melindrosas" e "que se não deve dar motivos para que se separem as províncias do império" (51).

Dessa forma, uns queriam a interpretação do Ato Adicional a fim de que as províncias do Império não se separassem. Outros não a queriam, e pelo mesmo motivo. Melhor dizendo, uns, outros e todos sentiam o mesmo temor: o do rompimento da unidade nacional.

(50) - Idem, ibidem, p. 126.

(51) - Anais, sessão de 16/7/1835, II, p.: 80. 